\title{
Originals
}

\section{Long-term and rapid regulation of ob mRNA levels in adipose tissue from normal (Sprague Dawley rats) and obese ( $d b / d b$ mice, fa/fa rats) rodents}

\author{
M. Igel ${ }^{1}$, H. Kainulainen ${ }^{2}$, A. Brauers ${ }^{1}$, W. Becker ${ }^{1}$, L. Herberg ${ }^{1}$, H.-G. Joost ${ }^{1}$ \\ ${ }^{1}$ Institute of Pharmacology and Toxicology, RWTH Aachen, Aachen, Germany \\ ${ }^{2}$ Institute of Medical Technology, University of Tampere, Tampere, Finland \\ ${ }^{3}$ Diabetes Research Institute, Düsseldorf, Germany
}

\begin{abstract}
Summary Increased levels of mRNA transcribed from the $o b$ gene in adipose tissue of obese/hyperinsulinaemic Zucker ( $f a / f a$ ) rats were detectable as early as 3 weeks after birth and continued to rise there after in parallel with body weight and serum insulin. mRNA levels of two other fat-specific genes (ARL4, FST44) were unaltered. In C57BL/KsJ $d b / d b$ mice, $o b$ mRNA levels also increased in parallel with body weight and serum insulin, and remained elevated in older animals when insulin levels decreased. In heterozygous control animals $(d b /+; f a / F a)$, mRNA levels were comparable with those in the homozygous controls. In normal Sprague Dawley rats, the $o b$ mRNA increased continuously, but more slowly than in Zucker rats, in parallel with body weight and insulin levels, and reached 15 times higher levels in the heaviest rats $(400 \mathrm{~g})$ studied. In Sprague Dawley rats made diabetic by an injection of streptozotocin, $o b$
\end{abstract}

mRNA levels were reduced by approximately $50 \%$ after $24 \mathrm{~h}$. A 24-h fasting period reduced the $o b$ mRNA by $50 \%$ in lean Sprague Dawley and $\mathrm{Fa} / \mathrm{Fa}$, but not in obese Zucker $f a / f a$ rats, although insulin levels were reduced in both groups. These data indicate that $o b$ mRNA levels increase in both normal and obese rodents in parallel with age, body weight and serum insulin, reflecting an early (Zucker rats, $d b$-mice) or slowly developing (Sprague Dawley rats) resistance to leptin and insulin. This increase does not appear to be mediated by the recently described rapid regulation of $o b$ mRNA by insulin, but seems to be due to a different, long-term control mechanism which signals the size of the fat depots. [Diabetologia (1996) 39: 758-765]

Keywords Leptin, $o b$ gene, gene expression, insulin resistance, obesity.
It has long been assumed that food intake is regulated by the adipose tissue mass through a feed-back mechanism which inhibits or stimulates hypothalamic nuclei [1]. Recently, this hypothesis has been proven by positional cloning of a single gene mutation in the C57BL/6J ob/ob mouse strain [2], the obese mutation $(o b)$, which causes a syndrome of hyperphagia and extreme obesity accompanied by numerous metabolic and hormonal alterations. This gene encodes a protein, tentatively designated leptin, which appears

Received: 27 October 1995 and in revised form: 5 December 1995

Corresponding author: Dr. H. G. Joost, Institut für Pharmakologie und Toxikologie, Medizinische Fakultät der RWTH Aachen, Wendlingweg 2, D-52057 Aachen, Germany to be secreted from adipose tissue. In the obese litter mates $(o b / o b)$ of the C57BL/6J strain, a nonsense mutation in codon 105 of the $o b$ gene generates an inactive protein which is responsible for excessive overeating, obesity and secondary metabolic alterations, e.g. a marked insulin resistance. Furthermore, mRNA levels of the $o b$ gene are 20 times higher in the obese mice than their lean litter mates, indicating that the lack of active leptin produces a counterregulatory increase in its gene expression. More recently, it has been shown that wild-type leptin indeed reduces food intake in $o b / o b$ mice [3-5]. Thus, leptin appears to be the crucial mediator in the feed-back control between adipose tissue and feeding behaviour.

Data from obese patients indicate that $o b$ mRNA levels are increased in approximate proportion with 
the body mass index [6]. So far, in none of these patients has a mutant leptin gene been found, suggesting that the increase in $o b$ mRNA levels is secondary to a reduced sensitivity to leptin. Increased levels of leptin mRNA have also been found in two strains of obese rats, the Zucker rat $f a / f a$ and the Otsuka Long Evans Tokushima fatty (OLETF) rat [7]. The cDNA sequence of leptin was normal in these strains, and neither of them carries a mutation near the $o b$ locus. Thus, their obesity appears to reflect a malfunction of the adipose tissue/ventromedial hypothalamus (VMH) feed-back regulation, possibly due to a defective leptin receptor. A similar conclusion has previously been drawn for the $d b / d b$ mouse on the basis of parabiosis experiments which indicated that the obese animals produced an excess of an anorexigenic factor which could inhibit overeating of the $o b / o b$ mouse [8]. Recently, this assumption was supported by the finding that mRNA levels of leptin were markedly elevated in the $d b / d b$ mouse [9].

The discovery of leptin has raised several important questions related to its function and also to the regulation of its synthesis. Therefore, we have studied mRNA levels of leptin in adipose tissue from morbidly obese (C57BL/KsJ $d b / d b$, KK, NZO mice, Zucker $f a / f a$ rats) and normal rodents (Sprague Dawley rats) in order to describe both long-term and rapid alterations. Based on the assumption that a defective leptin receptor in $d b / d b$ mice and Zucker rats gives rise to elevated $o b$ mRNA levels, we studied the time course of this elevation during the development of the metabolic syndrome in order to determine its onset and to correlate it with other parameters. In order to evaluate a possible rapid regulation of the $o b$ gene expression, the effects of fasting and streptozotocin diabetes were studied. The data indicate that leptin mRNA levels increase in obese rodents in parallel with age, body weight and serum insulin, reflecting an early (Zucker rats, $d b$-mice) or slowly developing (Sprague Dawley rats) resistance to leptin and insulin. Furthermore, the data suggest that this increase does not appear to be mediated by the recently described rapid regulation of $o b$ mRNA by insulin $[10,11]$, but seems to be due to a different, long-term control mechanism which signals the size of the fat depots.

\section{Materials and methods}

Animals. Mutant strains (C57BL/KsJHl-db/db, ZuckerHl-fa/ $f a, N Z O, K K, N O N)$ were bred in the Diabetes Research Institute, Düsseldorf. Sprague Dawley rats were bred in the colony of the Institut für Versuchstierkunde, Aachen. All animals were fed a standard laboratory diet and had free access to food and water. Homozygous and heterozygous $d b / d b$ mice and Zucker rats were identified by their breeding record. Sprague Dawley rats were rendered diabetic by a single injection of streptozotocin $(65 \mathrm{mg} / \mathrm{kg})$ as described previously [12]. The
"Principles of laboratory animal care" (NIH publication No. 85-23, revised 1985) were followed, and approval for the animal experiments, where necessary, was obtained from the Institution of Animal Care and Use at the University of Tampere, Finland, and the Regierungspräsident Düsseldorf, Germany.

Preparation of RNA. Animals were killed by decapitation, and subcutaneous, perirenal and gonadal fat was dissected and immediately frozen in liquid nitrogen. The samples were homogenized with a Polytron homogenizer in $4 \mathrm{~mol} / \mathrm{l}$ guanidine thiocyanate supplemented with $7 \%$ mercaptoethanol. Lysates were layered on a cesium chloride cushion $(5.88 \mathrm{~mol} / \mathrm{l})$ and centrifuged at $28000 \mathrm{rev} / \mathrm{min}$ (rotor SW40) for $29 \mathrm{~h}$ at $20^{\circ} \mathrm{C}$. Pelleted RNA was dissolved with $300 \mu \mathrm{l}$ sodium acetate/tris buffer, and was neutralized by addition of $50 \mu \mathrm{l} 2 \mathrm{~mol} / \mathrm{l}$ potassium acetate ( $\mathrm{pH} 5.5)$.

Preparation of a partial ob cDNA. Total RNA was isolated from 3T3-Ll cells as described previously [13], and 486 base pairs of the coding region of the $o b$ gene were amplified by polymerase chain reaction (PCR) with total RNA from differentiated 3T3-L1 cells [13] as the template (upstream primer 5'-CTG TGT CGG TTC CTG TGG-3'; reverse primer 5'GCA TTC AGG GCT AAC ATC-3'). The reaction product was separated on agarose and subcloned into the SmaI site of pUC19 (Sureclone kit: Pharmacia; Freiburg, Germany). Plasmid DNA was prepared and digested with BamHI/EcoRI in order to isolate the $o b$ cDNA.

Northern blot analysis. Samples of total RNA $(15 \mu \mathrm{g})$ were separated by electrophoresis on $1 \%$ agarose gels containing formaldehyde and transferred onto nylon membranes (Hybond $\mathrm{N}+$; Amersham-Buchler, Braunschweig, FRG). Before transfer, gels were stained with ethidium bromide in order to ascertain that equal amounts of total RNA had been separated. Probes were generated with the Klenow fragment of DNA polymerase I and $[\alpha-32 \mathrm{P}] \mathrm{dCTP}$ from the partial $o b \mathrm{cDNA}$ by random oligonucleotide priming [14]. The nylon membranes were hybridized at $42^{\circ} \mathrm{C}$, and blots were washed twice with $0.12 \mathrm{~mol} / \mathrm{l} \mathrm{NaCl} / 0.012 \mathrm{~mol} / \mathrm{l}$ sodium citrate $/ 0.1 \% \mathrm{SDS}$ and once with $0.015 \mathrm{~mol} / 1 \mathrm{NaCl} / 0.0015 \mathrm{~mol} / 1$ sodium citrate $/ 0.1 \%$ SDS. Autoradiographs were analysed with the LKB2400 laser densitometer and the software GelScan XL 2.0 from Pharmacia.

Other assays. Serum immunoreactive insulin was assayed with RIA kits from Pharmacia. Purified rat insulin (Novo Research Institute, Bagsvaerd, Denmark) was used as standard. Blood glucose was determined by an automated glucose oxidase method (Care Diagnostica, Voerde, Germany).

\section{Results}

Elevated levels of $m R N A$ of the ob gene in four strains of obese/hyperinsulinaemic mice. Northern blot hybridization of a mouse $o b$ cDNA probe with total RNA from adipose tissue yielded the anticipated single band at $4.5 \mathrm{~kb}$ [2]. Very low levels of $o b$ mRNA were detected in lean control mice $(\mathrm{KsJ}+/+$, homozygous controls of the C57BL/KsJ strain). As was reported previously [9], mRNA levels were approximately 10 times higher in the obese litter mates $(\mathrm{db} /$ $d b$, Fig. 1). High levels of leptin mRNA were also 


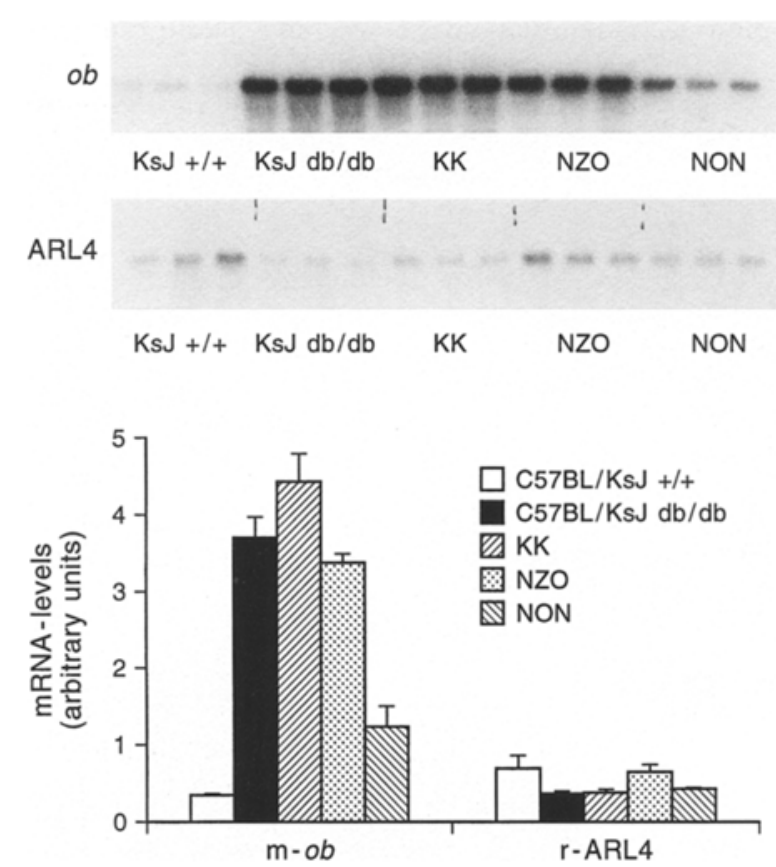

Fig. 1. Northern blot analysis of $o b$ gene expression in adipose tissue from different strains of obese mice. Total mRNA from adipose tissue of the indicated mouse strains (C57BL/KsJ, $\mathrm{KK}, \mathrm{NZO}, \mathrm{NON}$ ) was prepared as described and separated on agarose. Northern blots were probed with $o b$ and ARL4 CDNA, and the intensities of the 4.5 and $1.2 \mathrm{~kb}$ band (upper panel), respectively, were assayed by laser densitometry of autoradiographs (lower panel). The data represent means \pm SD of samples from three different animals

found in KK and NZO mice, whereas the NON strain showed a less pronounced increase (Fig. 1). Note that in KK, NZO and NON mice, the obese-hyperglycaemic syndrome is believed to be polygenic, and that normal congenic lines are not available for comparison. Thus, the lean litter mates of the $d b$-mice $(\mathrm{KsJ}+/+)$ have to be used as controls for the polygenic mutants.

Since the data as presented in Figure 1 are normalized per total RNA, the possibility has to be considered that obesity is paralleled by an increase of all mRNA species, or of the fat-specific mRNA species, in relation to the ribosomal RNA. Thus, in order to demonstrate the specificity of the observed increase, we assayed the levels of two other fat-specific transcripts which were recently cloned in our laboratory: the ras-related GTPase ARL4 [13] and a partial
cDNA sequence designated FST44 (Becker et al., unpublished data). As is illustrated in Figure 1, levels of ARL4 mRNA were somewhat variable, but were not significantly elevated in any of the obese/hyperglycaemic mice. Similarly (data not shown), FST44 mRNA levels were unaltered in the obese animals.

Table 1 summarizes the characteristics of the obese/hyperinsulinaemic animals in order to identify parameters which might predict, and thus be linked to, the elevation in $o b$ mRNA levels. There was no apparent correlation between blood glucose or insulin levels and $o b$ mRNA, since both parameters were normal in the NON mice in spite of a three-fold increase in $o b$ mRNA. In this experimental series, the best predictive parameter for the elevation of the $o b$ gene expression appeared to be the body weight, i.e. the adipose tissue mass, of the animals.

It appears reasonable to assume that the increase in the $o b$ gene expression in the $d b$ mice reflects a resistance to its product, leptin, and is a consequence of the hyperphagia and/or insulin resistance. Based on this assumption, we expected to find normal levels of leptin mRNA in heterozygous controls, since they exhibit a normal phenotype as far as hyperphagia and insulin levels are concerned. Indeed, as is depicted in Table 2, mRNA levels in the heterozygous animals $(\mathrm{db} /+)$ were similar to those in the homozygous controls. The small and insignificant difference was probably due to the greater age and weight of the heterozygous controls. Thus, the normal allele can fully compensate for the effect of the defective gene on obesity and $o b$ gene expression. Furthermore, similar data were obtained in the obese/hyperinsulinaemic Zucker rat $(f a / f a)$. In these rats, it has been previously shown that $o b$ mRNA levels are increased as compared with lean controls [7]. The data depicted in Table 2 extend these findings by showing that leptin mRNA levels are comparable in homozygous and heterozygous controls.

Time course of the increase in ob $m R N A$ levels in $C 57 B L / K s J d b / d b$ mice. In order to further investigate the relation between the $o b$ gene expression, body weight, blood glucose and serum insulin levels, these parameters were determined in $d b / d b$ mice of different ages (3, 4, 6 and 18 weeks). As is shown in Figure 2, $a b$ mRNA levels were significantly

Table 1. Characterization of the different strains of obese mice with regard to age, body weight, blood glucose and insulin levels

\begin{tabular}{|c|c|c|c|c|c|}
\hline & $\mathrm{KsJ}+/+$ & $\mathrm{KsJ} d b / d b$ & KK & $\mathrm{NZO}$ & NON \\
\hline Body weight (g) & $27.5 \pm 2.4$ & $52.4 \pm 2.5$ & $36.1 \pm 1.0$ & $56.6 \pm 2.3$ & $34.9 \pm 1.6$ \\
\hline Age (weeks) & 14 & 16 & 14 & 15 & 25 \\
\hline Blood glucose $(\mathrm{mmol} / \mathrm{l})$ & $8.3 \pm 1.0$ & $26.5 \pm 4.9$ & $14.6 \pm 4.3$ & $17.8 \pm 5.7$ & $7.4 \pm 0.4$ \\
\hline Serum insulin (pmol/l) & $78.0 \pm 34$ & $205.3 \pm 71$ & $760.0 \pm 553$ & $465.3 \pm 244$ & $72.7 \pm 26$ \\
\hline$O b$ mRNA (arbitrary units) & $0.4 \pm 0.1$ & $3.7 \pm 0.5$ & $4.4 \pm 0.6$ & $3.4 \pm 0.2$ & $1.2 \pm 0.5$ \\
\hline
\end{tabular}

Data represent means \pm SD for three animals 
Table 2. Levels of $o b$ mRNA in obese animals, homozygous and heterozygous lean litter mates of $d b$ mice and Zucker rats

\begin{tabular}{|c|c|c|c|c|c|c|}
\hline & $\mathrm{KsJ}+/+$ & $\mathrm{KsJ} d b /+$ & $\mathrm{Ks} \mathrm{J} d b / d b$ & $\mathrm{Fa} / \mathrm{Fa}$ & $f a / F a$ & $f a / f a$ \\
\hline Body weight (g) & $31.3 \pm 0.7$ & $35.6 \pm 1.5$ & $55.6 \pm 15.4$ & $280 \pm 22$ & $306 \pm 31$ & $463+29$ \\
\hline Age (weeks) & 22 & $27 / 32 / 38$ & 20 & 19 & 29 & 20 \\
\hline Blood glucose $(\mathrm{mmol} / \mathrm{l})$ & $7.3 \pm 1.9$ & $7.1 \pm 1.2$ & $25.5 \pm 3.7$ & $6.5 \pm 1.7$ & $4.8 \pm 0.7$ & $10.8 \pm 0.6$ \\
\hline Serum insulin $(\mathrm{pmol} / \mathrm{l})$ & $69.3 \pm 25$ & $104.0 \pm 26$ & $168.0 \pm 76$ & $17.3 \pm 2.7$ & $19.3 \pm 15$ & $304.7 \pm 94$ \\
\hline$O b$ mRNA (arbitrary units) & $2.0 \pm 0.1$ & $2.6 \pm 2.0$ & $8.3 \pm 0.9$ & $1.6 \pm 0.5$ & $2.6 \pm 2.2$ & $6.4 \pm 0.6$ \\
\hline
\end{tabular}

The data represent means \pm SD of three animals
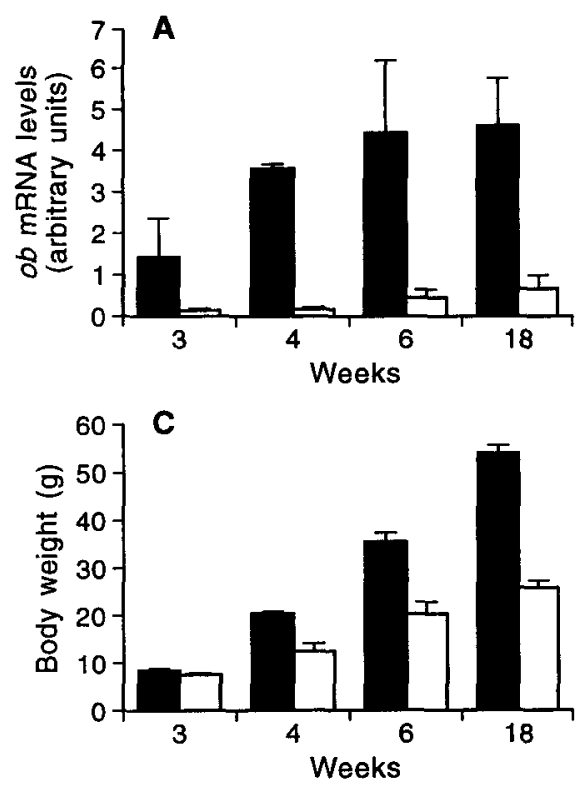
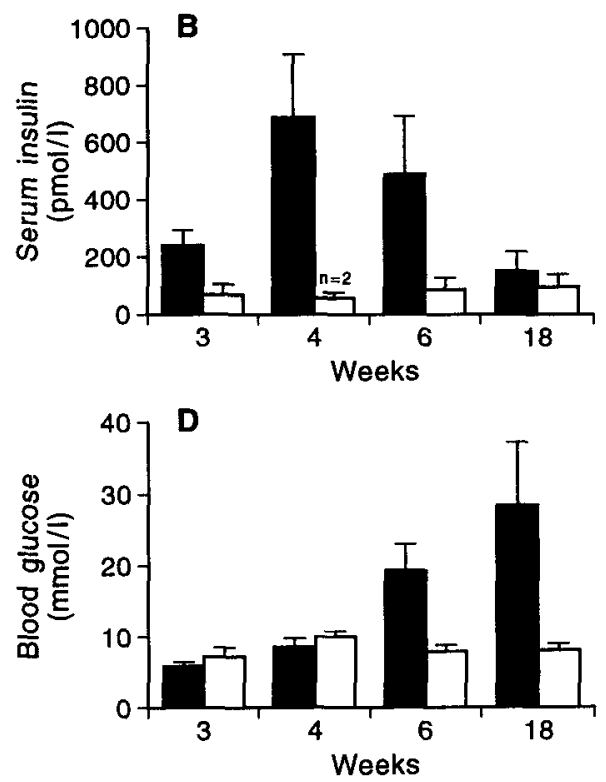

Fig. 2 A-D. $O b$ mRNA-levels in adipose tissue from C57BL/KsJ $d b / d b$ mice of different ages compared with the alterations in body weight, blood glucose, and serum insulin levels. Total RNA from obese animals $(d b / d b) \square$ and lean litter mates $\left(+I_{+}\right) \square$ of the indicated age was isolated and probed as described in the legend of Figure 1. Each data set are means $\pm S D$ of samples from three different animals increased at the earliest time point analysed (3 weeks). Thus, the effect appears to represent a very early event in the development of the metabolic disturbances in the $d b$ mouse. Similarly, hyperinsulinaemia and consequently insulin resistance were detectable at the earliest time point analysed. mRNA levels of leptin continued to rise thereafter (Fig. 2, panel B) and reached a plateau at 18 weeks. Insulin levels, in contrast, were markedly decreased due to the exhaustion of the islet organ [15] in the older animals (18 weeks). Blood glucose levels were normal at 3 and 4 weeks, and were significantly increased there after. As was anticipated from the previous experiments, levels of ARL4 were unaltered throughout (data not shown).

Time course of ob $m R N A$ levels in adipose tissue from $Z$ ucker fa/fa rats. Figure 3 illustrates a time course for the development of obesity and mRNA levels of leptin in relation to the hyperinsulinaemia in Zucker rats. As in the $d b$ mice, mRNA levels of leptin were significantly elevated at the earliest time point analysed ( 3 weeks) and continued to rise thereafter. In parallel, hyperinsulinaemia developed in the obese rats (Panel B). Unlike the $d b$ mice, the Zucker rats had normal blood glucose levels throughout (panel D) as has been reported previously [16].
Relation between body weight and leptin $m R N A$ levels in adipose tissue of Sprague Dawley rats. Aging Sprague Dawley rats develop obesity and a moderate hyperinsulinaemia, and have previously been used as a model of insulin resistance [17]. Therefore, we studied adipose tissue from normal Sprague Dawley rats of different weights. As is illustrated in Figure 4, there was an almost proportional increase in $o b$ mRNA levels with body weight. Similarly, levels of serum insulin increased roughly in parallel with the body weight (Table 3 ). Both $o b$ mRNA and insulin levels in the highest weight group $(400 \mathrm{~g})$ were still considerably lower than those in $300 \mathrm{~g}$ Zucker rats. It should be noted, however, that a direct comparison of age and weight between Sprague Dawley and Zucker rats is inappropriate because of their largely different growth rate. As is shown by a comparison of the body lengths at 13 weeks, Sprague Dawley rats grow much faster than the Zucker rats (Zucker rats, $17.5 \mathrm{~cm}$; Sprague Dawley rats, $30 \mathrm{~cm}$ ).

Effects of fasting on leptin $m R N A$ levels in adipose tissue of normal and Zucker fa/fa rats. Recently, it was described that fasting produces a rapid decrease of leptin mRNA levels in rat adipose tissue which was probably mediated by a decrease in the serum insulin [10]. Confirming this finding, we obtained similar 

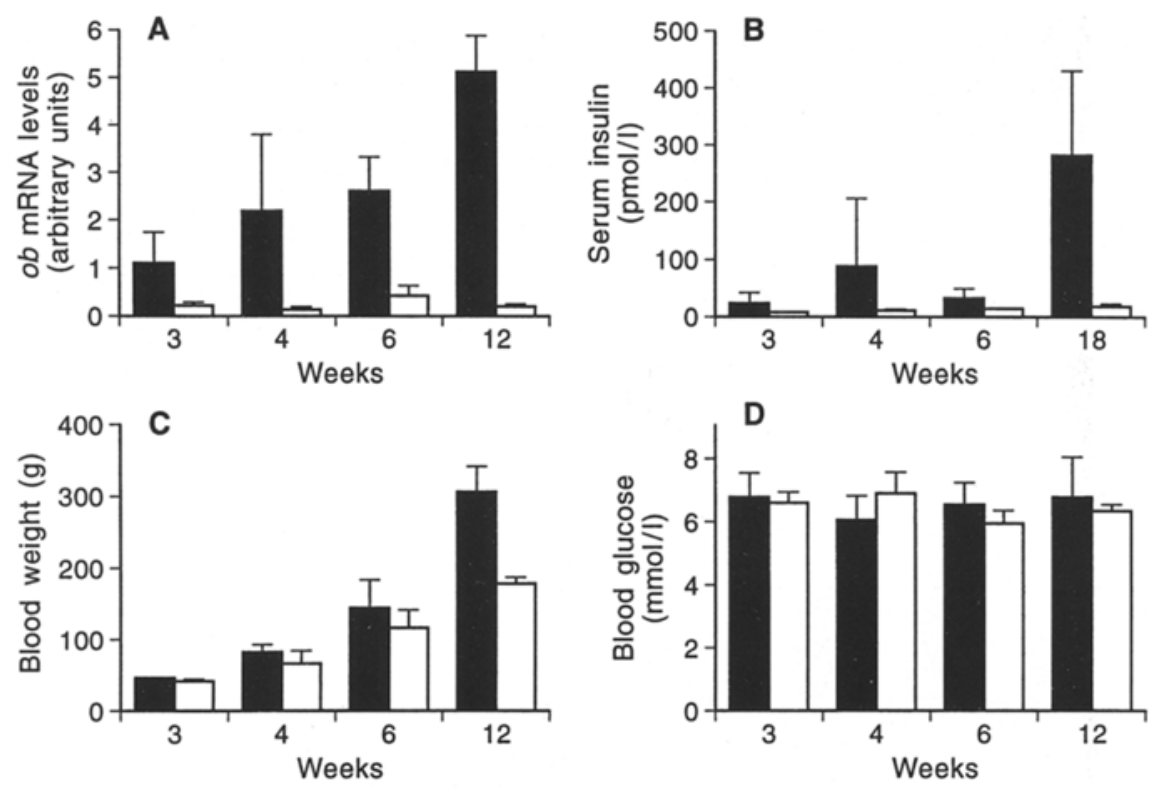

Fig. 3 A-D. $O b$ mRNA-levels in adipose tissue from Zucker ( $f a / f a)$ rats of different ages compared with alterations in body weight, blood glucose and insulin levels. Total RNA from obese animals $(f a / f a)$ and lean litter mates $(\mathrm{Fa} / \mathrm{Fa}) \square$ of the indicated age was isolated and probed as described in the legend of Figure 1. Each data set are means $\pm S D$ of samples from three different animals

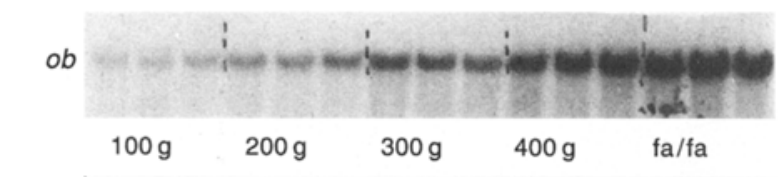

ARL4

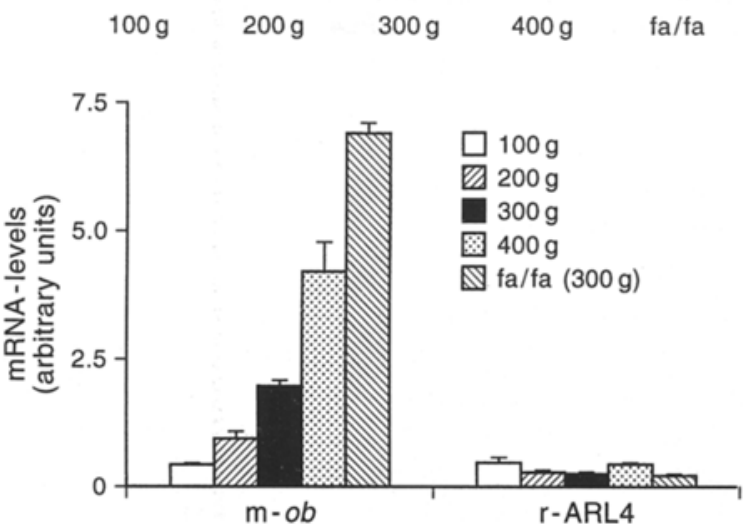

Fig. 4. $O b$ mRNA levels in adipose tissue from Sprague Dawley rats of different ages and body weights. Total RNA was isolated from animals of the indicated weight and probed as described in the legend of Figure 1. Each data set are means \pm $\mathrm{SD}$ of samples from four different animals

data with the Sprague Dawley rats after a 24-h fasting period: mRNA levels of leptin were decreased by $60 \%(1.5 \pm 0.8$ vs 3.990 .44 in the controls, mean \pm SD arbitrary densitometry units), whereas those of ARL4 were unaltered $(0.26 \pm 0.02$ in both groups). The same experiment was performed with obese Zucker rats and their lean controls (Fig. 5). Surprisingly, fasting failed to significantly affect leptin mRNA levels in the obese animals, whereas the expected $50 \%$ decrease was seen in the lean controls.
Note, however, that the absolute levels in the obese animals were much higher than those in the lean controls. As anticipated, fasting resulted in a reduction of serum glucose and insulin levels in both normal and obese animals.

Effect of streptozotocin-diabetes on ob $m R N A$ levels in adipose tissue of normal rats. In order to further characterize the relation between serum insulin and $o b$ mRNA levels, the effect of an experimental reduction of insulin levels by the diabetogenic agent streptozotocin was studied. Streptozotocin reduced $o b$ mRNA levels by approximately $65 \%$ (Fig. 6, upper panel), whereas the levels of mRNA of ARL4 were unaltered. Similar data demonstrating a marked decrease in leptin mRNA levels 5 days after injection of streptozotocin were very recently published by others [11]. Extending these findings, the lower panel of Figure 6 illustrates a time course of the effect of streptozotocin. Rats were rendered diabetic by injection of the agent, and $o b$ mRNA levels were assayed $1,2,4,8$ and 16 days after the injection. The $o b$ mRNA was reduced as early as 1 day after injection, in parallel with the steep increase in blood glucose which reflects the abolition of insulin secretion from the endocrine pancreas. No further decrease in $o b$ mRNA was observed after the first day of diabetes. Thus, the experiment revealed a relatively rapid regulation of $o b$ mRNA in response to the streptozotocin diabetes.

\section{Discussion}

The role of leptin as a major regulator of food intake has recently been established convincingly by the finding that exogenously applied leptin reduces the 
Table 3. Metabolic characteristics of Sprague Dawley rats of different age

\begin{tabular}{lccccc}
\hline & SD & SD & SD & SD \\
\hline Body weight (g) & 100 & 200 & 300 & 400 & 300 \\
Age (weeks) & 4 & 6 & 8 & 13 & 13 \\
Blood glucose (mmol/l) & $7.8 \pm 0.2$ & $8.8 \pm 0.3$ & $7.7 \pm 0.1$ & $8.6 \pm 1.3$ & $6.6 \pm 1.4$ \\
Serum insulin (pmol/l) & $10.0 \pm 0.7$ & $32.0 \pm 6.0$ & $28.0 \pm 2.7$ & $61.3 \pm 16.7$ & $230.0 \pm 121$ \\
Ob mRNA (arbitrary units) & $0.4 \pm 0.4$ & $0.9 \pm 0.1$ & $2.0 \pm 0.1$ & $4.2 \pm 0.6$ & $6.9 \pm 0.2$ \\
ARL4 mRNA (arbitrary units) & $0.5 \pm 0.1$ & $0.3 \pm 0.01$ & $0.3 \pm 0.02$ & $0.5 \pm 0.03$ \\
\hline
\end{tabular}

Data are means \pm SD of three animals
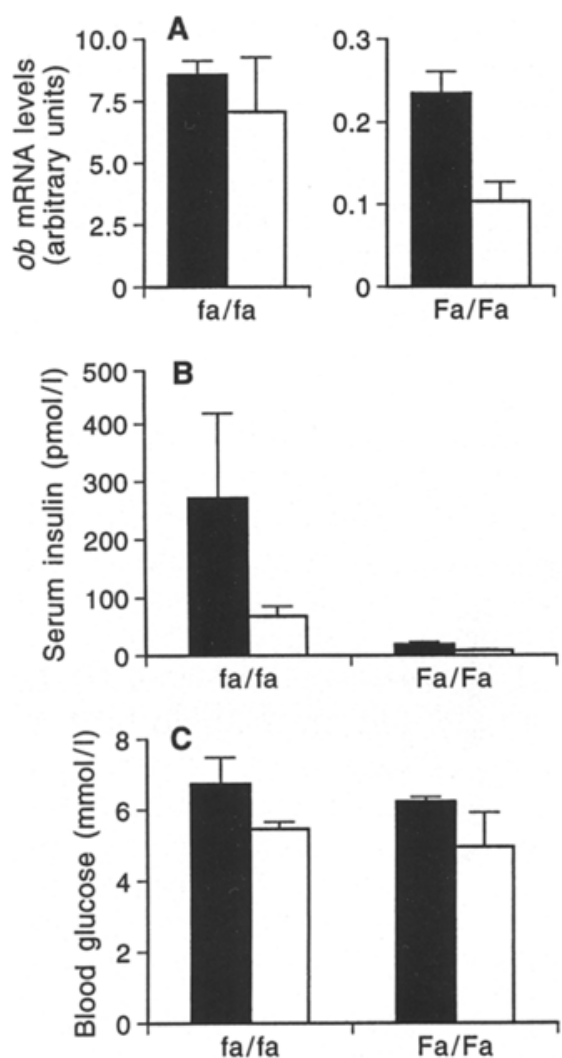

Fig. 5 A-C. Effect of fasting on serum insulin, blood glucose and $o b$ mRNA in adipose tissue from obese Zucker rats $(\mathrm{fa} / \mathrm{fa})$ and lean litter mates $(\mathrm{Fa} / \mathrm{Fa})$. Total RNA was isolated as described in the legend of Figure 1 and probed with mouse $o b$ cDNA. The data represent means \pm SD of samples from three different animals; note the different ordinate scale on the right side of panel A. Control, $\mathbf{\square} ; 24$-h fasting,

food intake in obese $(o b / o b)$ and normal mice [4]. In addition, the finding that mRNA levels of leptin in mice carrying the nonsense mutation are markedly elevated suggested a counterregulatory control via the $o b$ gene expression [2]. Extending these earlier findings, the present data indicate that mRNA levels transcribed from the $o b$ gene are regulated by longterm adaptation, in apparent correlation with the size of the fat depots, as well as through rapid control mechanisms in normal and obese rodents. In proportion to the degree of obesity, marked increases in mRNA levels were observed in several hereditary forms of early obesity as well as in moderately obese
A



B
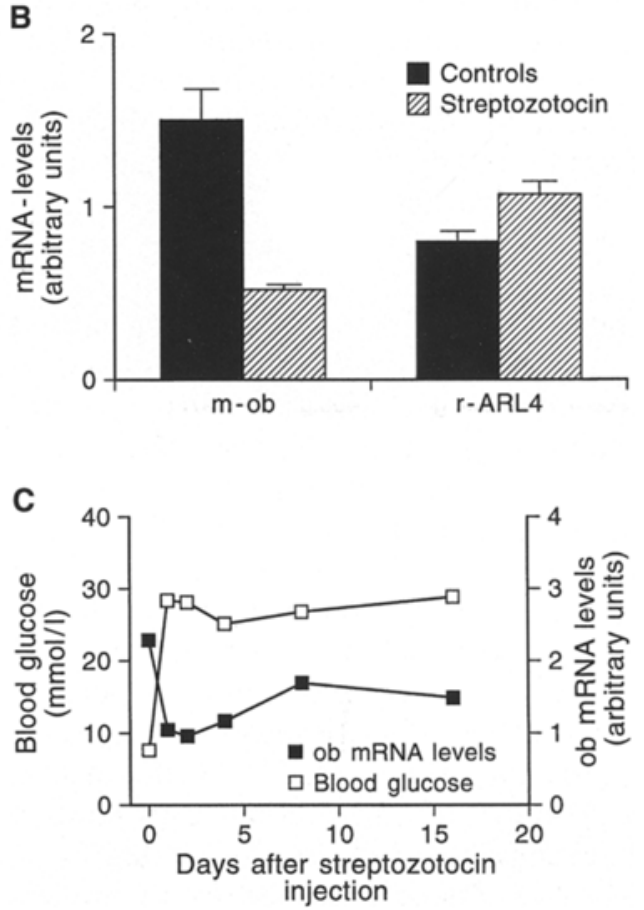

Fig. 6 A-C. Effect of streptozotocin diabetes on mRNA levels of leptin in epididymal adipose tissue. Male Sprague Dawley rats were rendered diabetic by a single injection of $65 \mathrm{mg} / \mathrm{kg}$ streptozotocin. Total RNA was isolated 1 week after the injection $(\mathbf{A}, \mathbf{B})$ as described in the legend of Figure 1 , and was probed with either mouse $o b$ (m-ob) or rat ARL4 (r-ARL4) cDNA. The data are means \pm SD from three animals. C: Time course of the effect of streptozotocin. Total RNA was isolated at the indicated time points after injection of streptozotocin, and was probed with mouse $o b$ cDNA. Each data point was obtained with at least two animals

Sprague Dawley rats. Thus, an increase in the $o b$ gene expression and consequently resistance to leptin not only occurs in rare mutants of early obesity but also during the course of aging in 'normal' rodents. These findings are compatible with the previous 
hypothesis [2] that leptin, the product of the $o b$ gene, is a crucial component of a feed-back mechanism controlling body weight through feeding behaviour, and that it is the size of the adipose tissue stores that controls the feed-back inhibition of food intake.

The present data and two recent studies $[10,11]$ indicate that leptin mRNA levels are also rapidly regulated as in fasting or streptozotocin-treated animals, presumably through alterations of the serum insulin levels. Blood glucose levels can be ruled out as a factor regulating the expression of the $o b$ gene, because the time course of the metabolic syndrome in the $d b /$ $d b$ mouse indicated that hyperglycaemia emerged much later than the increase in leptin mRNA levels. In addition, fasting and streptozotocin produced similar effects on leptin mRNA levels, but opposite effects on serum glucose. By the same token, we believe that serum lipids which are elevated in streptozotocin-diabetic animals are unlikely candidates for the regulation of the $o b$ gene expression. Insulin levels, however, were altered in parallel with mRNA levels of leptin in fasting and streptozotocin diabetes. Thus, it appears safe to conclude that insulin, or a parameter of adipocyte metabolism controlled by insulin, mediates the short-term regulation of the $o b$ gene expression.

Two key findings of the present study suggest that the long-term increase in $o b$ mRNA levels observed in the obese rodents can be dissociated from alterations of the serum insulin levels. Leptin mRNA levels remained elevated in older $d b / d b$ mice in spite of a dramatic decrease in serum insulin. Secondly, fasting decreased serum insulin levels in Zucker rats but failed to produce a reduction in leptin mRNA levels proportional to that seen in the controls. Thus, we suggest that the age and weight-dependent increase in leptin mRNA levels in the obese rodents is unrelated to the rapid regulation exerted by serum insulin levels, and reflects an additional long-term control mechanism which signals the size of the fat depots.

Both $d b$ mice and Zucker rats represent models for the study of obesity and insulin resistance [1820]. It is well established that these strains carry mutations in homologous genes [21] and that differences in the severity of the diabetes are due to the different genetic backgrounds of these mutants. It appears reasonable to conclude on the basis of the present and previous data [8] that both strains are resistant to leptin and develop hyperphagia and obesity because of this defect, and that the continuous increase in the $o b$ gene expression is secondary to the leptin resistance. Consequently, one would have to conclude that all other metabolic alterations observed in the obese animals, in particular insulin resistance, are secondary to hyperphagia. The present data indicate, however, that the marked elevation in mRNA levels of leptin in the obese litter mates started at an early age at which hyperphagia is hardly noticeable.
Hyperinsulinaemia, i.e. insulin resistance, appeared to start at a similar time point and roughly paralleled the $o b$ gene expression thereafter. Thus, whereas the increases in serum insulin and the $o b$ gene expression appear to coincide, the role of hyperphagia as a cause of both alterations is not entirely clear. Interestingly, leptin appears to exert metabolic effects independent of the reduction of food intake, since the lowest doses applied in $o b / o b$ mice normalized blood glucose and body temperature but failed to reduce food intake [3]. Thus, it is tempting to speculate on a peripheral action of leptin which controls both insulin sensitivity and body temperature.

Acknowledgements. The authors are indebted to Ms. A. Schraven and Ms. S. Breitwieser for skilful technical assistance. This study was supported by the Deutsche Forschungsgemeinschaft (SFB 351) and the Bundesministerium für Bildung, Forschung und Technologie.

\section{References}

1. Friedman JM, Leibel RL (1992) Tackling a weighty problem. Cell 69: 217-220

2. Zhang Y, Proenca R, Maffei M, Barone M, Leopols L, Friedman JM (1994) Positional cloning of the mouse obese gene and its human homologue. Nature 372: 425-432

3. Pelleymounter MA, Cullen MJ, Baker MB et al. (1995) Effects of the obese gene product on body weight regulation in ob/ob mice. Science 269: 540-543

4. Halaas JL, Gajiwala KS, Maffei M et al. (1995) Weight-reducing effects of the plasma protein encoded by the obese gene. Science 269: 543-546

5. Campfield LA, Smith FJ, Guisez Y, Devos R, Burn P (1995) Recombinant mouse $o b$ protein: evidence for a peripheral signal linking adiposity and central neural networks. Science 269: 546-549

6. Considine RV, Considine EL, Williams CJ et al. (1995) Evidence against either a premature stop codon or the absence of obese gene mRNA in human obesity. J Clin Invest 95: 2986-2988

7. Murakami T, Shima K (1995) Cloning of rat obese cDNA and its expression in obese rats. Biochim Biophys Res Commun 209: 944-952

8. Coleman DL (1973) Effects of parabiosis of obese with diabetic and normal mice. Diabetologia 9: 294-298

9. Maffei M, Fei H, Lee GH et al. (1995) Increased expression in adipocytes of $o b$ RNA in mice with lesions of the hypothalamus and with mutations at the db locus. Proc Natl Acad Sci USA 92: 6957-6960

10. Saladin R, De Vos P, Guerre-Millo M et al. (1995) Transient increase in obese gene expression after food intake or insulin administration. Nature 377: 527-529

11. MacDougald AO, Hwang CS, Fan H, Lane MD (1995) Regulated expression of the obese gene product (leptin) in white adipose tissue and 3T3-L1 adipocytes. Proc Natl Acad Sci USA 92: 9034-9037

12. Kainulainen $H$, Breiner $M$, Schürmann A, Marttinen A, Virjo A, Joost HG (1994) In vivo glucose uptake and glucose transporter proteins GLUT1 and GLUT4 in heart and various types of skeletal muscle from streptozotocin-diabetic rats. Biochim Biophys Acta 1225: 275282 
13. Schürmann A, Breiner M, Becker W et al. (1994) Cloning of two novel ADP-ribosylation factor-like proteins and characterization of their differential expression in 3T3-L1 cells. J Biol Chem 269: 15683-15688

14. Feinberg AP, Vogelstein B (1983) A technique for radiolabeling DNA restriction endonuclease fragments to high specific activity. Anal Biochem 132: 6-13

15. Coleman DI, Hummel KP (1967) Studies with the mutation, diabetes, in the mouse. Diabetologia 3: 238-248

16. Bach A, Schirardin H, Bauer M, Schaeffer A, Weryha A (1981) Age-related changes in biological parameters in Zucker rats. Lipids 16: 841-848

17. Hissin PJ, Foley JF, Wardzala LJ et al. (1982) Mechanism of insulin-resistant glucose transport activity in the enlarged adipose cell of the aged, obese rat. Relative depletion of intracellular glucose transport systems. J Clin Invest 70: 780-790

18. Herberg L, Coleman DL (1977) Laboratory animals exhibiting obesity and diabetes syndromes. Metabolism 26: 5999

19. Zaninetti D, Crettaz M, Jeanrenaud B (1983) Dysregulation of glucose transport in hearts of genetically obese $\mathrm{fa}$ fa rats. Diabetologia 25: 525-529

20. Galante P, Maerker E, Scholz R et al. (1994) Insulin-induced translocation of GLUT4 in skeletal muscle of insulin-resistant Zucker rats. Diabetologia 37: 3-9

21. Truett GE, Bahary N, Friedman JM, Leibel RL (1991) Rat obesity gene fatty (fa) maps to chromosome 5: evidence for homology with the mouse gene diabetes $(\mathrm{db})$. Proc Natl Acad Sci USA 88: 7806-7809 